\title{
mRNA expression profiles for corticotrophin-releasing factor (CRF), urocortin, CRF receptors and CRF-binding protein in peripheral rat tissues
}

\section{S M Baigent and P J Lowry}

School of Animal and Microbial Sciences, University of Reading, Reading RG6 6AJ, UK

(Requests for offprints should be addressed to S Baigent; Email: s.m.baigent@reading.ac.uk)

\begin{abstract}
The expression and activities of corticotrophinreleasing factor $(\mathrm{CRF})$, urocortin $(\mathrm{UCN})$, the CRF-binding protein (CRF-BP) and CRF receptors in rat brain have been well documented; however, information regarding their peripheral distributions remains incomplete. Given the multiple immunomodulatory effects of peripherally administered CRF and UCN and the high levels of CRF receptor type 2 (CRF-R2) mRNA and protein expressed in the heart, the lymphoid organs and heart have become targets for some of the latest CRF-related research. Here we demonstrate the presence of UCN mRNA in both the rat spleen and human Jurkat T-lymphoma cells using 3'-RACE (rapid amplication of cDNA ends) PCR. Following on from these initial results, we used semiquantitative RT-PCR to carry out a comprehensive study assessing the relative amounts of CRF, UCN,
\end{abstract}

CRF-R1, CRF-R2 and CRF-BP mRNAs in the brain, thymus, spleen and heart of normal, untreated rats. The rank orders of mRNA abundance in each of the tissue types were as follows: for $\mathrm{CRF}$, brain $>>$ thymus $=$ spleen $=$ heart; for $\mathrm{UCN}$, heart $\geq$ brain $>$ thymus $>$ spleen; for CRF$\mathrm{R} 1$, brain $>>$ thymus $>$ spleen (absent in heart); for CRF-R2, brain=heart $>$ thymus $>$ spleen; and CRF-BP was only detectable in the brain. We have provided evidence for the existence of $\mathrm{CRF}, \mathrm{UCN}$, CRF-R1 and CRF-R2 expression in resting immune cells, with UCN expression being particularly predominant in the rat thymus and human Jurkat cells. Additionally, the high levels of UCN mRNA detected in heart corresponded to the high expression of CRF-R2 mRNA, suggesting an important role for UCN/CRF-R2 coupling in this tissue.

Fournal of Molecular Endocrinology (2000) 25, 43-52

\section{INTRODUCTION}

Corticotrophin-releasing factor (CRF) is a 41 amino acid neuropeptide, best known for its role in triggering adrenocorticotrophin $(\mathrm{ACTH})$ release from the pituitary (Vale et al. 1981, Linton et al. 1985). In the rat, both CRF and its binding protein (CRF-BP) are abundantly expressed in the brain (Potter et al. 1991, 1992). The high-affinity pituitary $\mathrm{CRF}$ receptor (CRF-R1) is also located in many regions of the brain (Chen et al. 1993, Perrin et al. 1993, Chang et al. 1994, Potter et al. 1994). In rats and mice, the more recently cloned CRF-R2 $\alpha$ is found mainly in hypothalamic nuclei (Lovenberg et al. 1995a,b) and its splice variant, CRF-R2 $\beta$, predominates in the heart and in skeletal muscle (Kishimoto et al. 1995, Lovenberg et al. 1995a,b). CRF-R2 $\gamma$ is expressed in human brain (Kostich et al. 1998).
In 1995, the gene for urocortin (UCN), a novel peptide sharing $50 \%$ amino acid homology with $\mathrm{CRF}$, was cloned from rat midbrain (Vaughan et al. 1995). UCN has a 4-fold higher affinity than CRF for CRF-R1 and a 40-fold higher affinity for CRF-R2 (Vaughan et al. 1995), suggesting that $\mathrm{UCN}$ may be the predominant ligand for CRF-R2 in the brain and heart. Despite this, only one report has so far suggested the presence of UCN mRNA in rat cardiac myocytes (Okosi et al. 1998). In vitro studies suggest that the peptide may play roles in protecting cardiac myocytes from cell death induced by hypoxia (Okosi et al. 1998) and stimulating atrial natriuretic peptide secretion (Ikeda et al. 1998). Intravenous injection of UCN produces dosedependent increases in cardiac contractility, heart rate, cardiac output and coronary blood flow in conscious sheep (Parkes et al. 1997). There have been no reports of CRF-R1 in the heart and few 
reports of CRF mRNA detection (Muglia et al. 1994)

A limited number of reports suggest that $\mathrm{UCN}$ and $\mathrm{CRF}$ are produced by peripheral immunocytes and may act in a paracrine manner to induce local immune responses. CRF immunoreactivity has been detected within inflammatory sites (Crofford et al. 1992, 1993, Elenkov et al. 1999) whilst both the peptide and mRNA have been reported in thymic and splenic cell populations (Chowdrey et al. 1994, Kravchenco \& Furalev 1994, Brouxhon et al. 1998, Ottaviani et al. 1998), and in peripheral blood leukocytes (Stephanou et al. 1990). Only recently has UCN mRNA been detected in immune cells (Bamberger et al. 1998). When these peptides are injected peripherally, pro-inflammatory (Karalis et al. 1991, Singh et al. 1999) and anti-inflammatory (Torpy et al. 1999) responses have been observed. The existence of CRF and UCN in immune cells correlates with reports of CRF receptors being present on mouse spleen cells (Webster et al. 1990) and blood lymphocytes (Singh \& Fudenberg 1988). These early studies made use of radiolabelled ovine CRF to detect cell binding sites, so that it was impossible to conclude whether the binding sites were CRF receptors or membrane-bound CRF-BP. Only recently have CRF-R1-specific mRNA and protein been found in mouse spleen cells (Radulovic et al. 1999).

From these studies, we can now begin to understand the actions of peripherally administered $\mathrm{CRF}$ and UCN on the heart and immune system; however, it is difficult to relate these actions to the endogenous release of peptide because information regarding $\mathrm{CRF}, \mathrm{UCN}$ and $\mathrm{CRF}$ receptor expression in peripheral tissues remains incomplete. For example, CRF-R2 or membrane-bound CRF-BP expression in immune tissues has never been reported. Additionally, publications on the subject remain very limited and there are no reports which have examined and compared the expression of all the components of the CRF system (CRF, UCN, CRF-R1, CRF-R2 and CRF-BP) in selected peripheral tissues. There is still much confusion as to which ligand/receptor system predominates in these tissues.

The aim of this work was first to use $3^{\prime}$-RACE PCR to detect the presence of $\mathrm{mRNA}$ for UCN in rat spleen and for $\mathrm{UCN}, \mathrm{CRF}$ and $\mathrm{CRF}$ receptors in the human Jurkat (T-lymphoma) cell line. $3^{\prime}$-RACE PCR is the most reliable technique for the detection of cDNA, as the template is amplified through the polyA tail, negating the chances of amplifying genomic DNA. However, this type of PCR is not quantitative. The results of the 3 '-RACE experiments prompted us to carry out a comprehensive RT-PCR study to ascertain the presence or absence of all five components of the CRF system in the heart, thymus and spleen of normal, untreated rats using brain as a positive control tissue. The relative abundance of each transcript in these tissues was also assessed.

\section{MATERIALS AND METHODS}

\section{RNA extraction}

Two male and two female NEDH rats were killed and the brain, heart, thymus and spleen of each animal were immediately washed in PBS, cut into small pieces and homogenised in Trireagent (Sigma-Aldrich, Poole, Dorset, UK) using a Silverson electric homogeniser (Silverson, Chesham, Bucks, UK). Total mRNA was extracted following the Tri-reagent protocol, a modification of the technique used by Chomczinski \& Sacchi (1987). mRNA was isolated using Qiagen's Oligotex mRNA Extraction Kit (Qiagen, Crawley, West Sussex, UK). The same technique was used to isolate mRNA from Jurkat cells, but in this case, cells were lysed by trituration instead of homogenisation. Between 1 and $10 \mu \mathrm{g} \mathrm{mRNA}$ were obtained from 100-250 $\mu \mathrm{g}$ total RNA, depending on the type of tissue extracted.

\section{Rat spleen and human Jurkat cell Marathon cDNA synthesis and 3 '-RACE PCR}

One microgram of spleen mRNA isolated from one of the male rats and $1 \mu \mathrm{g}$ human Jurkat cell mRNA were used to synthesise double-stranded Marathonadapted cDNA pools using the technique described by the Clontech Marathon cDNA Synthesis protocol (Chenchik et al. 1995). The doublestranded cDNAs were diluted 100-fold with nuclease-free water and $2 \mu \mathrm{l}$ of the diluted cDNAs were used in each first-round PCR reaction. Specific primers were used in conjunction with a Marathon adaptor primer in order to carry out 3'-RACE PCR on each cDNA pool. KlenTaq polymerase containing Taq antibody (Clontech, Basingstoke, Hants, UK) was used in all PCR reactions. The forward primer sequences are illustrated in Table 1 together with the estimated product sizes and the annealing temperatures used. The estimated product sizes are based on the known database sequences with the longest $3^{\prime}$-ends and represent the minimum product length expected. The two human CRF receptor primers were designed to anneal to both the CRF-R1 and CRF-R2 cDNA. Two rounds of PCR were carried out in order to visualise specific products. The $50 \mu \mathrm{l}$ 
TABLE 1. Summary of the 3 '-RACE PCR primer sequences used to amplify CRF, UCN and CRF receptor cDNAs from Jurkat cell cDNA and UCN from rat spleen cDNA. The annealing temperatures used and the expected product sizes are also shown. Touchdown PCR (Don et al. 1991) involved the use of high annealing and extension temperatures during the first ten PCR cycles (five cycles at $72{ }^{\circ} \mathrm{C}$, five at $70{ }^{\circ} \mathrm{C}$ ), followed by 20 cycles at $68{ }^{\circ} \mathrm{C}$

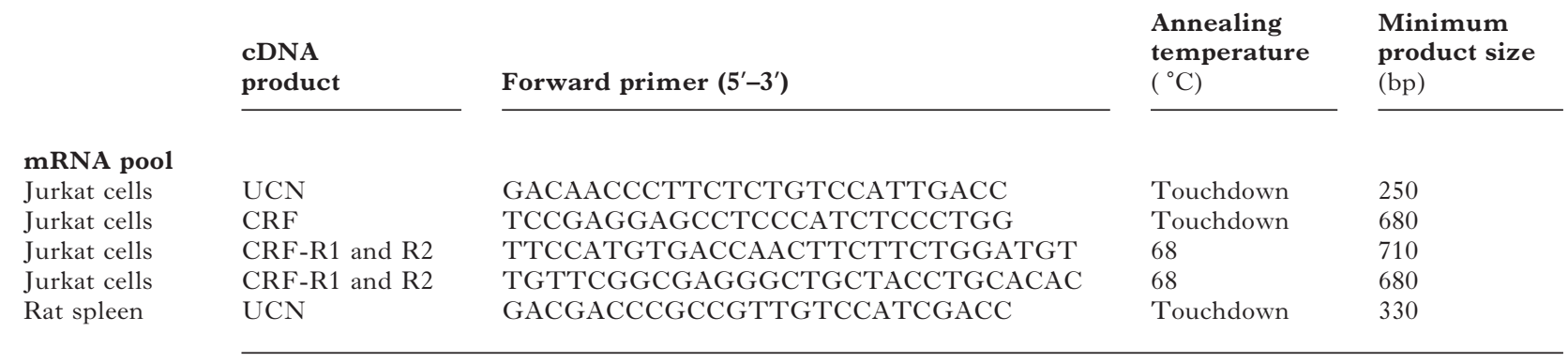

PCR mix for the first 30 cycles contained $1 \mu \mathrm{M}$ of a specific forward primer, $1 \mu \mathrm{M}$ first-round adaptor primer (5'-CCATCCTAATACGACTCACTATA GGGC-3'), $200 \mu \mathrm{M}$ dNTP mixture, $2 \mu$ diluted cDNA and $1 \cdot 1 \mu \mathrm{g}$ KlenTaq enzyme and Taq Start antibody. Amplification was performed on a Bio-Rad thermocycler (Bio-Rad, Hemel Hempstead, Herts, UK). Thirty microlitres of the amplified products were run on a $1.5 \%$ agarose gel containing $0.001 \%$ ethidium bromide and visualised under an ultraviolet transilluminator (UVP Inc., San-Gabriel, CA, USA). At this stage the gel lanes appeared blank. Two microlitres of the remaining first-round mixtures were then diluted 25 -fold with nuclease-free water and $2 \mu \mathrm{l}$ were re-entered into a second-round PCR. The reaction mix was identical to the first-round mix with the exception that the first-round adaptor primer had been replaced with a nested second-round adaptor primer (5'ACGACTCACTATAGGGCTCGAGCGGC - $3^{\prime}$ ) for increased specificity. 'Touchdown' PCR was developed by Don et al. (1991) in order to increase the specificity of a PCR reaction involving one specific primer with an annealing temperature above $70{ }^{\circ} \mathrm{C}$ and one non-specific primer (adaptor primer) with an annealing temperature of $68-70{ }^{\circ} \mathrm{C}$. This prevents the formation of single adaptor primer products during the first five to ten PCR cycles due to the preferential hybridisation of the specific primer to the cDNA template. The conditions used for the Touchdown PCR reaction were as follows: step $1,95{ }^{\circ} \mathrm{C}, 5 \mathrm{~min}$; step $2,95{ }^{\circ} \mathrm{C}, 30 \mathrm{~s}$; step 3 , $72{ }^{\circ} \mathrm{C}, 3 \mathrm{~min}$; step 4 , four more cycles back to step 2; step $5,95{ }^{\circ} \mathrm{C}, 30 \mathrm{~s}$; step $6,70{ }^{\circ} \mathrm{C}, 3 \mathrm{~min}$; step 7 , four more cycles back to step 5 ; step $8,95^{\circ} \mathrm{C}$, $30 \mathrm{~s}$; step 9, $68^{\circ} \mathrm{C}, 3 \mathrm{~min}$; step 10,19 more cycles back to step 8 ; step $11,68^{\circ} \mathrm{C}, 6 \mathrm{~min}$. All other reactions were as follows: step $1,95^{\circ} \mathrm{C}, 5 \mathrm{~min}$; step $2,95^{\circ} \mathrm{C}, 30 \mathrm{~s}$; step $3,68^{\circ} \mathrm{C}, 3 \mathrm{~min}$; step 4,29 more cycles back to step

www.endocrinology.org
2; step 5, $68{ }^{\circ} \mathrm{C}, 6 \mathrm{~min}$. Second-round products were visualised on an agarose gel as described above and bands similar in molecular weight to the predicted sizes were excised. Identity of the products was confirmed by purification of gel slices using the Gene Clean Kit (BIO 101 Inc., Vista, CA, USA), followed by cloning into pGEM T-Easy vector (Promega, Southampton, Hants, UK) and transformation of competent XL-1 Escherichia coli bacteria (Stratagene, La Jolla, CA, USA). Bacterial colonies were grown overnight in Luria broth containing $100 \mu \mathrm{g} / \mathrm{ml}$ ampicillin (Sigma-Aldrich) and plasmid preparations were performed using Qiagen's mini plasmid preparation kit. Purified plasmid preparations were subjected to cycle sequencing on an ALF express sequencer (Pharmacia, St Albans, Herts, UK).

\section{Semi-quantitative RT-PCR of rat tissue mRNA}

mRNA pools were isolated from the brain, spleen, thymus and heart of three rats (one male and two females) as described above. RT-PCR was performed using the R'T Access Kit (Promega). The reaction volume of $25 \mu$ l contained final concentrations of $200 \mu \mathrm{M}$ dNTP mixture, $1 \mathrm{mM}$ magnesium sulphate, $1 \mu \mathrm{M}$ forward primer, $1 \mu \mathrm{M}$ reverse primer, $0 \cdot 1$ units $/ \mu \mathrm{AMV}$ reverse transcriptase and $0 \cdot 1$ units/ $\mu \mathrm{l} \mathrm{Tfl}$ polymerase. The amounts of mRNA used in each reaction were between 10 and $50 \mathrm{ng}$. The annealing temperatures and cycle numbers varied for different reactions. Briefly, reverse transcription was carried out at $48{ }^{\circ} \mathrm{C}$ for $45 \mathrm{~min}$ (step 1) and was immediately followed by the PCR reaction (step $2,95^{\circ} \mathrm{C}, 5 \mathrm{~min}$; step $3,95{ }^{\circ} \mathrm{C}, 30 \mathrm{~s}$; step $4,63-74{ }^{\circ} \mathrm{C}, 1 \mathrm{~min}$; step 5, $68^{\circ} \mathrm{C}, 2$ min; step $6,22-44$ more cycles back to step 3 ; step $7,68^{\circ} \mathrm{C}, 8 \mathrm{~min}$ ). The sequences of the primer pairs, annealing temperatures used for the 


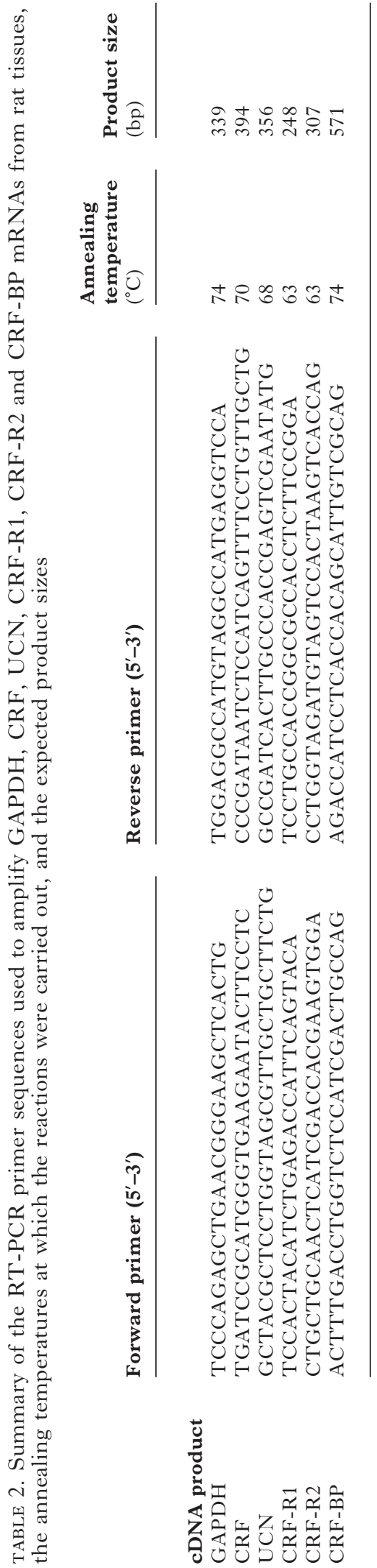

reactions and the sizes of the expected products are summarised in Table 2. All primers were synthesised by Sigma-Genosys, Pampisford, Cambridgeshire, UK. The primer pairs selected for CRF-R1, CRF-R2 and CRF-BP mRNA detection were designed to amplify across at least one intron, ruling out the possibility of identical size bands resulting from genomic DNA amplification. This was not the case for the glyceraldehyde 3-phosphate dehydrogenase (GAPDH), CRF and UCN primers as the important coding regions within the genomic DNAs are intronless. Control PCR reactions described below were used to overcome the possibility of amplifying genomic DNA in these circumstances. PCR products were electrophoresed, cloned and characterised as described above. The RT-PCR technique described here was used for two semi-quantitative experiments: one using single high concentrations of the mRNA samples, and the other using serial dilutions of the same mRNAs in order to estimate with more accuracy the relative amounts of mRNAs in each tissue.

Semi-quantitative RT-PCR using neat mRNA samples The aim of this experiment was to ascertain either the presence or absence of CRF, UCN, CRF-R1, CRF-R2 and CRF-BP mRNA in the heart, spleen and thymus, using brain as a positive control tissue for all reactions. Quality of mRNA samples was assessed by carrying out 40-cycle PCR reactions for the housekeeping gene, GAPDH, for each mRNA sample, together with control reactions in which no reverse transcriptase was added.

Amounts of mRNA placed into each GAPDH reaction tube were balanced by carrying out serial 4-fold dilutions of the mRNA samples $(1: 1,1: 4$, 1:16 and 1:64) and amplifying GAPDH mRNA for 23 cycles, at which point the PCR reaction was found to have almost reached saturation. The intensity of the resulting bands was observed in order to adjust the mRNA dilutions accordingly for future reactions. The dilution titring described above was carried out separately for each of the three animals.

Using the optimised concentrations of mRNA, $\mathrm{PCR}$ reactions testing for the presence of CRF, UCN, CRF-R1, CRF-R2 and CRF-BP were carried out over 40 cycles using the primer pairs and annealing temperatures specified in Table 2. Control reactions in which no reverse transcriptase was added were carried out for every PCR experiment. All reactions were repeated between one and three more times for each of the three sets of samples. Experiments in which the positive control (brain) consistently yielded a bright band on 
an agarose gel after 40 cycles, but in which no PCR products were detected in the peripheral tissues, were instead carried out over a total of 60 PCR cycles. In these circumstances, RT-PCR amplification was carried out for 30 cycles and $2 \mu \mathrm{l}$ of the resulting product mixture were re-entered into a second 30-cycle round of PCR as described previously, but excluding the AMV reverse transcriptase from all the reaction tubes.

Semi-quantitative RT-PCR using serial dilutions mRNA samples The above experiments which resulted in bright gel bands after 40 PCR cycles in one or more of the peripheral tissues were repeated using serial 4-fold dilutions (1:1, 1:4, 1:16 and 1:64) of previously optimised concentrations of mRNA, and RT-PCR amplification was carried out for 45 cycles. This time, the decreasing intensities of the gel bands corresponding to increasing mRNA dilutions, allowed us to assess by eye the relative abundance of UCN, CRF-R1 and CRF-R2 mRNAs in the peripheral tissues and the brain. Each experiment was carried out three times. Similar banding patterns were observed on each occasion.

\section{RESULTS}

\section{Rat spleen and human Jurkat cell Marathon 3'-RACE PCR}

After two rounds of PCR had been carried out on the rat spleen mRNA using the forward UCN primer and the reverse Marathon adaptor primers, two strong bands of approximately $450 \mathrm{bp}$ and $650 \mathrm{bp}$ were visible on an agarose gel (Fig. 1A, lane $3)$. Subsequent cloning and sequencing of the lower molecular weight product showed it to have an actual size of $479 \mathrm{bp}$. The first $283 \mathrm{bp}$ of this fragment exactly matched the 3 '-end of the most complete rat UCN cDNA sequence in the Genbank database (Vaughan et al. 1995, accession number U33935); however, bases 283-429 provided a novel sequence, assumed to be an extension of the non-coding $3^{\prime}$-end of the rat UCN gene. Bases 430-479 incorporated the Marathon adaptor and adaptor primer sequences as expected. The $650 \mathrm{bp}$ product was not sequenced. The control reaction, in which no cDNA was added, was completely clear of amplified products (Fig. 1A, lane 2).

The Jurkat cell cDNA pool was also found to contain UCN cDNA (Fig. 1B, lane 3); however, of the gel bands resulting from the PCR experiments designed to amplify CRF, CRF-R1 and CRF-R2 cDNAs, none was found to represent the expected products (results not shown). Because the $3^{\prime}$-RACE technique amplifies the complete $3^{\prime}$-ends of cDNAs

www.endocrinology.org
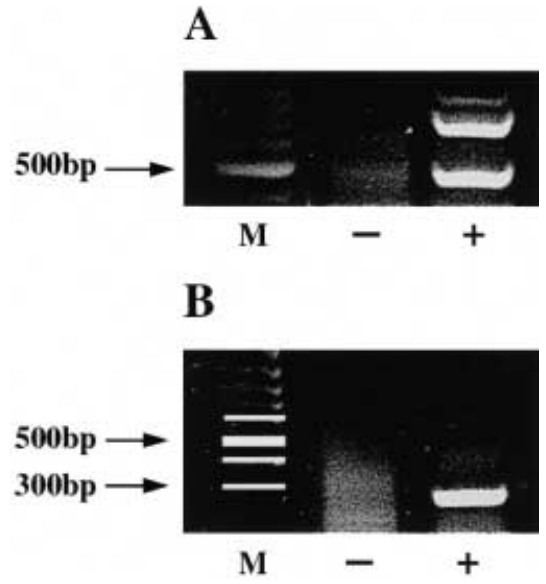

FIGURE 1. Second-round 3'-RACE Marathon PCR amplification of UCN cDNA from rat spleen (A) and human Jurkat cells (B). Two rounds of PCR each consisting of 30 cycles of the Touchdown protocol were carried out. The $450 \mathrm{bp}$ product in panel $\mathrm{A}$ and the $250 \mathrm{bp}$ product in panel $\mathrm{B}$ were cloned and the sequences were found to match the $3^{\prime}$ ends of the rat and human UCN sequences respectively. Abbreviations: 'M' 100 bp DNA ladder marker (lane 1), '- ' control reaction (no cDNA added) (lane 2), '+' test reaction (cDNA added) (lane 3).

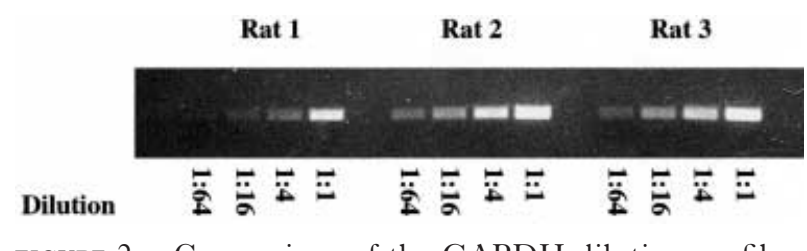

FIGURE 2. Comparison of the GAPDH dilution profiles for the three rat brain mRNA pools. Twenty-three cycles of RT-PCR were carried out at an annealing temperature of $74{ }^{\circ} \mathrm{C}$.

including the poly-A tail, it does not result in false positives due to genomic DNA contamination; however, only one of the primers is specific to the cDNA of interest and therefore multiple bands are often observed. Consequently, it is sometimes more difficult to amplify a less-abundant mRNA using this technique, whereas RT-PCR uses two specific primers, allowing for a more focused PCR reaction which can be used for semi-quantification of the selected mRNAs.

\section{Semi-quantitative RT-PCR using neat mRNA samples}

Figure 2 illustrates the optimised GAPDH dilution profiles from each of the three brain mRNA pools, 


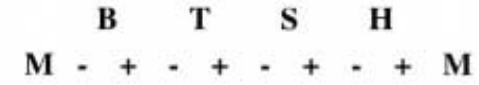
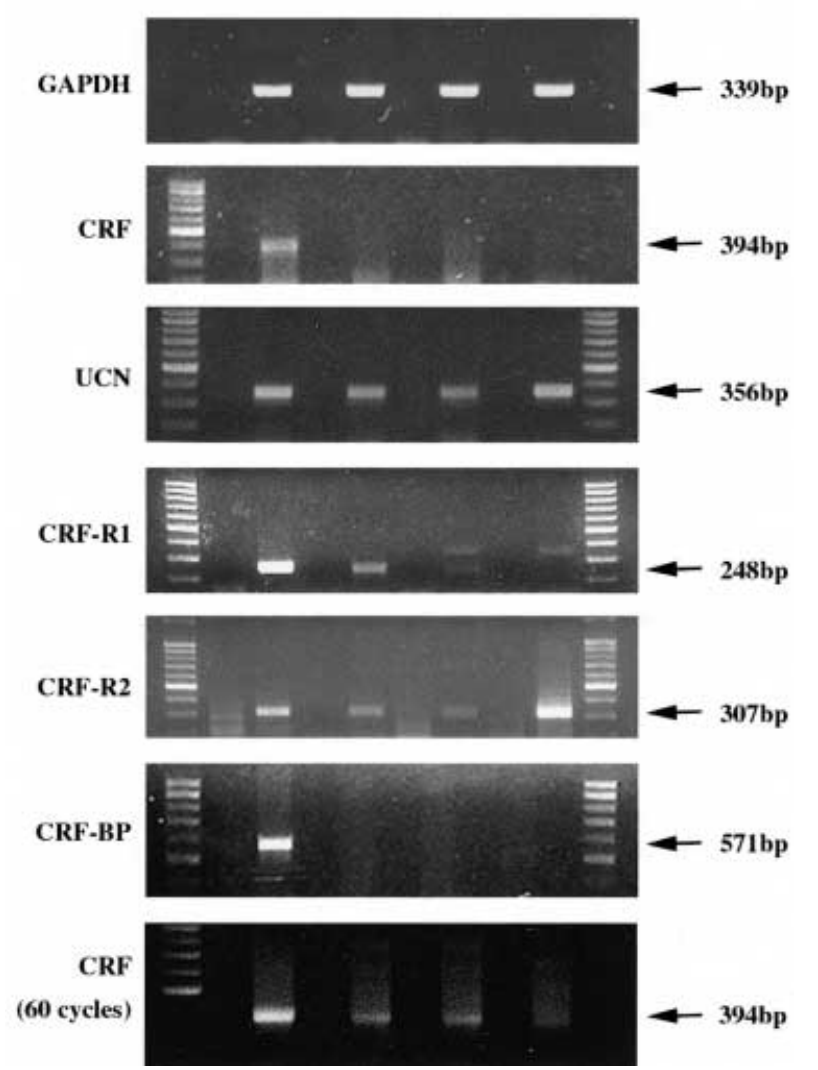

FIGURE 3. Semi-quantitative RT-PCR carried out on neat samples of brain (B), thymic $(\mathrm{T})$, splenic $(\mathrm{S})$ and heart $(\mathrm{H})$ mRNA in order to detect the presence of GAPDH, CRF, UCN, CRF-R1, CRF-R2 and CRF-BP transcripts in these tissues. Forty PCR cycles were carried out for all reactions. Key to other abbreviations: 'M' 100 bp DNA ladder marker, '-' control reaction without reverse transcriptase, '+' PCR reaction with the addition of reverse transcriptase. The brain provided a positive control test for all six primer pairs. Approximately equal amounts of mRNA were added to each reaction.

showing that similar amounts of mRNA were used for each animal. The brightness of the GAPDH bands representing the spleen, thymus and heart mRNAs of a single animal were then optimised to match that of the brain GAPDH from the same animal.

For the main experiments (Fig. 3), 40 PCR cycles were carried out. Once again, GAPDH expression was observed in all tissues. The control lanes showed no evidence for either contamination or the presence of genomic DNA. In all but a few experiments the positive control (brain) yielded a bright band on an agarose gel after 40 cycles, and of these valid PCR reactions, the relative intensities of the bands were generally very consistent. The control lanes were clear in every experiment. The gel bands illustrated in Fig. 3 represent the majority of the results obtained and were able to be reproduced on at least four occasions. The product bands were all of the predicted sizes and their identities were confirmed by DNA sequencing on two separate occasions. The only PCR reactions which yielded more than one band in a single lane were those carried out using CRF-R1 primers on spleen and heart mRNA. In these cases, the lower molecular weight band was of the expected size for CRF-R1 cDNA and the $350 \mathrm{bp}$ product was found to represent an unrelated gene. Brain mRNA provided an ideal positive control for all the PCR reactions, as demonstrated by the presence of bright bands in the third lane $(\mathrm{B}+)$ of each gel. This suggested that the selected primer pairs were similarly efficient at amplifying their target mRNAs.

The peripheral immune tissues (thymus and spleen) shared very similar expression patterns to each other. In these tissues, CRF cDNA was not detected after 40 cycles, yet was just detectable after 60 PCR cycles in both tissues (see Fig. 3, lower panel). Forty cycles were sufficient, however, to amplify UCN cDNA, which appeared to be relatively more abundant in the thymus than in the spleen. In fact, on several occasions splenic UCN proved impossible to amplify, demonstrating how little is expressed in the spleen. cDNA for CRF-R1 was consistently detected in the thymus after 40 cycles, although bands were pale compared with the brain positive control lane. Splenic CRF-R1 was just detectable after 40 cycles (the lower molecular weight $248 \mathrm{bp}$ band), and on several occasions it was not possible to visualise the amplified product. Expression of CRF-R2 cDNA was also evident in the immune tissues, once again to a lesser extent than the expression levels observed in the brain. Finally, there was no evidence for CRF-BP mRNA being present in either the thymus or the spleen, even after 60 amplification cycles.

RT-PCR reactions carried out on heart mRNA showed that, whilst UCN and CRF-R2 mRNA were abundant in this tissue, low CRF expression was only evident after 60 PCR cycles and CRF-R1 and CRF-BP mRNAs were absent.

\section{Semi-quantitative RT-PCR using serial dilutions of mRNA}

This experiment allowed us to estimate with greater accuracy the relative abundance of UCN, CRF-R1 


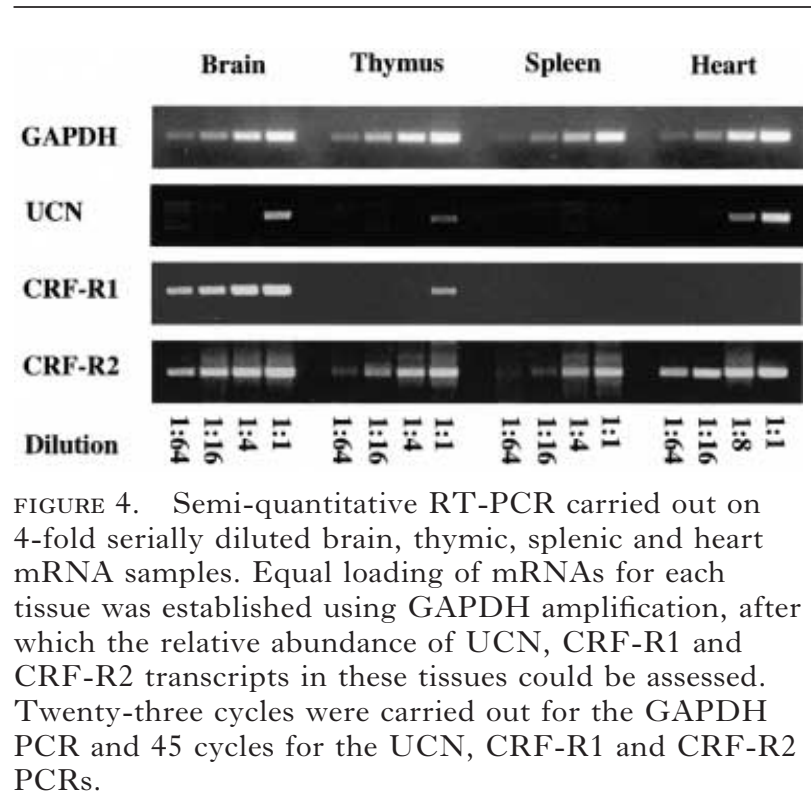

and CRF-R2 mRNAs in the brain, thymus, spleen and heart. These PCRs were carried out three times each, with similar results being obtained on each occasion. Typical results are shown in Fig. 4.

The GAPDH dilution profiles illustrated approximately equal loading of mRNAs from the four different tissues. Our UCN data suggest that, compared with the heart, there are 2- to 3-fold lower concentrations of UCN mRNA in the brain, 5 - to 6 -fold lower concentrations in the thymus, and in the spleen UCN cDNA was not detected in this experiment. CRF-R1 mRNA expression predominated in the brain, in which levels were more than 64-fold higher than in the thymus. In the spleen, CRF-R1 expression was too low to be visible on the gel photograph illustrated here. No CRF-R1 mRNA was detected in the heart. CRF-R2 levels in the brain and heart appeared to be almost identical, with 4- to 6-fold lower concentrations in the thymus and approximately 16-fold lower levels in the spleen. Table 3 summarises the combined results from all of the semi-quantitative RT-PCR experiments.

\section{DISCUSSION}

In this study, we first demonstrated the presence of $\mathrm{UCN}$ mRNA in normal unstimulated rat spleen and human Jurkat cells using $3^{\prime}$-RACE PCR. This technique has the advantage over RT-PCR in that the amplified products have complete $3^{\prime}$-cDNA ends and any contaminating genomic DNA will not
TABLE 3. Summary of the relative abundance of CRF, UCN, CRF-R1, CRF-R2 and CRF-BP mRNAs in the brain, thymus, spleen and heart. The summary is based on the combined data from Figs 3 and 4 . In the case of inconsistencies between the two figures, the result showing the greatest abundancy of mRNA has been selected for this table

\begin{tabular}{|c|c|c|c|c|}
\hline & Brain & Thymus & Spleen & Heart \\
\hline $\mathrm{CRF}$ & +++ & $*$ & $*$ & $*$ \\
\hline UCN & +++ & ++ & + & +++ \\
\hline CRF-R1 & +++ & ++ & + & - \\
\hline CRF-R2 & +++ & ++ & ++ & +++ \\
\hline CRF-BP & +++ & - & - & - \\
\hline
\end{tabular}

interfere with the PCR reactions. However, $3^{\prime}$ RACE PCR gives no indication of the relative amounts of $\mathrm{UCN}$ in these tissues as multiple bands are often observed, so RT-PCR was used for a more specific semi-quantitative approach. Peripheral rat tissues were the focus of these experiments. High levels of UCN and CRF-R2 mRNA were observed in the heart, with low levels of $\mathrm{CRF}$ and no evidence for the existence of CRF-R1 or CRF-BP mRNA. In the immune tissues, UCN, CRF-R1 and CRF-R2 mRNAs were all detected, but once again, CRF mRNA levels appeared especially low and CRF-BP mRNA was not detected. Splenic CRF-R1 and UCN mRNAs were just detectable in the first set of experiments, but not in the experiments using serial dilutions of mRNA. The fixed amounts of mRNA being used for all the RT-PCR studies meant that less-abundant amplified products were at the limit of detection on an agarose gel. In these circumstances either pale bands were observed or bands were completely absent.

The experiments were designed to allow us to compare levels of a single mRNA type (e.g. UCN) in the four different tissues studied. We made the assumption that in all the rat tissues, the number of GAPDH mRNA molecules per microgram of each mRNA pool is the same. Although this may not strictly be the case, GAPDH dilution or cycle titring still remain the most commonly exploited techniques for comparing mRNA levels in various tissues. We therefore suggest that the rank orders of mRNA abundance in each of the tissue types is as follows: for $\mathrm{CRF}$, brain $>>$ thymus=spleen = heart; for $\mathrm{UCN}$, heart $\geq$ brain $>$ thymus $>$ spleen; for $\mathrm{CRF}$ $\mathrm{R} 1$, brain $>>$ thymus $>$ spleen $>$ heart; for $\mathrm{CRF}-\mathrm{R} 2$, brain $=$ heart $>$ thymus $>$ spleen; and for CRF-BP, brain $>>$ thymus $=$ spleen $=$ heart . 
Our RT-PCR studies not only confirm the findings of others (Webster et al. 1990, Kravchenco \& Furalev 1994, Bamberger et al. 1998, Brouxhon et al. 1998, Okosi et al. 1998, Ottaviani et al. 1998, Radulovic et al. 1999), but also demonstrate several novel concepts.

First, we have shown that CRF-R2 expression is not confined solely to the brain and heart, but the mRNA is also abundant in the thymus and is expressed to a lesser extent in the spleen. The tissue expression profiles for the CRF-R2 correlate well with the expression profiles for $\mathrm{UCN}$, but do not correlate with those of CRF. Likewise, the rank order of abundance for CRF-R1 mRNA in the various tissues follows a similar pattern to that for $\mathrm{CRF}$, quite distinct from the UCN rankings. This provides additional evidence for the coupling of $\mathrm{UCN}$ with the CRF-R2 and CRF with the CRF-R1.

This study has allowed us to compare expression levels of the CRF family members and their receptors in four tissues removed from normal, untreated rats. Further studies comparing mRNA levels in normal and immune-stimulated animals would provide a greater insight into the importance of both constitutive and induced ligand production. It has already been demonstrated that CRF-R1 protein levels in splenic neutrophils and macrophage precursors are increased 17-fold after i.p. administration of lipopolysaccharide (Radulovic et al. 1999) and that a 9-fold decrease in heart CRF-R2 mRNA levels occurs after i.p. interleukin (IL)-1 injection (Heldwein et al. 1999).

The facts that UCN and CRF are capable of acting through the same receptors and that we have detected both the CRF-R1 and CRF-R2 mRNAs in the spleen and thymus confuses the issue as to which ligand/receptor system may be the most important in the immune system. The expression of UCN mRNA by Jurkat cells, without any evidence for $\mathrm{CRF}$ or CRF receptor expression suggests that the subsets of leukocytes may differentially express the ligands and their receptors. Further evidence to support this theory is provided by other groups. Bamberger et al. (1998) were unable to detect CRF mRNA in Jurkat cells or unstimulated lymphocytes which contained UCN mRNA, and Radulovic et al. (1999) localised CRF-R1 immunoreactivity to splenic neutrophils and granulocyte macrophage precursors, yet the protein was not expressed in splenic T- or B-lymphocytes or peripheral blood leukocytes. Stephanou et al. (1990) showed that relatively large numbers of cells were required in order to detect CRF mRNA in peripheral blood lymphocytes and neutrophils by Northern blot analysis and Crofford et al. (1993) were unable to amplify CRF mRNA from unstimulated LEW/N rat spleen total RNA extract; however, 18 days after the induction of adjuvant-induced arthritis, splenic CRF levels were readily detectable. In these and other studies CRF and CRF-R1 expression were found to be very low in unstimulated cells, yet production was significantly increased in response to inflammatory stimuli. Peripherally secreted CRF may not only have direct pro-inflammatory effects (Karalis et al. 1991, Singh et al. 1999), but also appears to have the ability to inhibit release of IL-1 and -6 by human mononuclear cells in vitro (Hagan et al. 1992), induce both ACTH and $\beta$-endorphin release from leukocytes (Smith et al. 1986) and induce opioid production from immune cells in inflamed tissue (Schäfer et al. 1994). Jessop et al. (1997) found that treatment of rat splenocytes in vitro with an antisense oligodeoxynucleotide complementary to CRF mRNA inhibited the proliferation of these cells.

Given that our experiments showed apparently higher levels of UCN and CRF-R2 mRNA in the unstimulated spleen and thymus compared with CRF and CRF-R1 mRNA, this may suggest that $\mathrm{UCN}$ and its preferred receptor are produced constitutively and may be important in the functioning of resting immune cells. In the event of $\mathrm{UCN}$ and CRF-R2 expression being upregulated in response to immune stimuli, potent responses may be expected due to the 40-fold higher affinity of $\mathrm{UCN}$ for CRF-R2 compared with CRF. UCN also has a 4-fold higher affinity for CRF-R1 and has been shown to trigger mast cell degranulation via activation of type 1 receptors (Singh et al. 1999).

Direct effects of UCN on heart cells in vitro and in vivo include changes in heart rate and coronary blood flow (Parkes et al. 1997), stimulation of atrial natriuretic peptide release (Ikeda et al. 1998) and protection of cell death after hypoxia (Okosi et al. 1998). The high levels of UCN mRNA that we detected in the heart may account for some of these actions occurring in a paracrine fashion and suggest that $\mathrm{UCN}$ is a more important ligand than $\mathrm{CRF}$ in this tissue.

In summary, we have provided evidence for the existence of CRF, UCN, CRF-R1 and CRF-R2 expression in resting immune cells, with $\mathrm{UCN}$ expression being particularly predominant in the rat thymus and human Jurkat cells. The high-affinity receptor for UCN (CRF-R2) was not evident in Jurkat cells, yet was present in the thymus, possibly suggesting a paracrine, rather than autocrine action of UCN within the thymus. The high levels of UCN mRNA detected in heart corresponded to the high expression of CRF-R2 mRNA suggesting an important role for UCN/CRF-R2 coupling in this tissue. 


\section{ACKNOWLEDGEMENTS}

This work was funded by the UK Wellcome Trust and Medical Research Council.

\section{REFERENCES}

Bamberger CM, Wald M, Bamberger A, Ergun S, Beil FU \& Schulte HM 1998 Human lymphocytes produce urocortin, but not corticotropin-releasing hormone. Fournal of Clinical Endocrinology and Metabolism 83 708-711.

Brouxhon SM, Prasad WV, Joseph SA, Felten DL \& Bellinger DL 1998 Localization of corticotropin-releasing factor in primary and secondary lymphoid organs of the rat. Brain Behaviour and Immunity 12 107-122.

Chang C, Pearse RV, O'Connell S \& Rosenfeld MG 1994 Identification of a seven transmembrane helix receptor for corticotropin-releasing factor and sauvagine in mammalian brain. Neuron 11 1187-1195.

Chen R, Lewis KA, Perrin MH \& Vale WW 1993 Expression cloning of a human corticotropin-releasing-factor receptor. PNAS 90 8967-8971.

Chenchik A, Moqadam F \& Siebert P 1995 Marathon cDNA amplification: a new method for cloning full-length cDNAs. CLONTECHniques $\mathbf{X}$ 5-8.

Chomczinski P \& Sacchi N 1987 Single-step method of RNA isolation by acid guanidinium thiocyanate-phenolchloroform extraction. Analytical Biochemistry 162 156-159.

Chowdrey HS, Lightman SL, Harbuz MS, Larsen PJ \& Jessop DS 1994 Contents of corticotropin-releasing hormone and arginine vasopressin immunoreactivity in the spleen and thymus during a chronic inflammatory stress. Fournal of Neuroimmunology 53 17-21.

Crofford LJ, Sano H, Karalis K, Webster EL, Goldmuntz EA, Chrousos GP \& Wilder RL 1992 Local secretion of corticotropin-releasing hormone in the joints of Lewis rats with inflammatory arthritis. Fournal of Clinical Investigation $902555-2564$.

Crofford LJ, Sano H, Karalis K, Friedman TC, Epps HR, Remmers EF, Mathern P, Chrousos GP \& Wilder RL 1993 Corticotropin-releasing hormone in synovial fluids and tissues of patients with rheumatoid arthritis and osteoarthritis. Fournal of Immunology 151 1587-1596.

Don R, Cox P, Wainwright B, Baker K \& Mattick J 1991 'Touchdown' PCR to circumvent spurious priming during gene amplification. Nucleic Acids Research 194008.

Elenkov IJ, Webster EL, Torpy DJ \& Chrousos GP 1999 Stress, corticotropin-releasing hormone, glucocorticoids, and the immune/inflammatory response: acute and chronic effects. Annals of the New York Academy of Sciences 876 1-11.

Hagan P, Poole S \& Bristow AF 1992 Immunosuppressive activity of corticotrophin-releasing factor: inhibition of interleukin-1 and interleukin- 6 production by human mononuclear cells. Biochemical fournal 281 251-254.

Heldwein KA, Duncan JE, Stenzel P, Rittenberg MB \& Stenzel-Poore MP 1999 Endotoxin regulates corticotropinreleasing hormone receptor 2 in heart and skeletal muscle. Molecular and Cellular Endocrinology 131 $167-172$.

Ikeda K, Tojo K, Sato S, Ebisawa T, Tokudome G, Hosoya T, Harada M, Nakagawa O \& Nakao K 1998 Urocortin, a newly identified corticotropin-releasing factor-related mammalian peptide, stimulates atrial natriuretic peptide and brain natriuretic peptide secretions from neonatal rat cardiomyocytes. Biochemical and Biophysical Research Communications 250 298-304.

Jessop DS, Harbuz MS, Snelson CL, Dayan CM \& Lightman SL 1997 An antisense oligodeoxynucleotide complementary to corticotropin-releasing hormone mRNA inhibits rat splenocyte proliferation in vitro. Fournal of Neuroimmunology 75 135-140.

Karalis K, Sano H, Redwine J, Listwak S, Wilder RL \& Chrousos GP 1991 Autocrine or paracrine inflammatory actions of corticotropin-releasing hormone in vivo. Science 254 421-423.

Kishimoto T, Pearse RV, Lin CR \& Rosenfeld MG 1995 A sauvagine/corticotropin-releasing factor receptor expressed in heart and skeletal muscle. PNAS 92 1108-1112.

Kostich WA, Chen A, Sperle K \& Largent BL 1998 Molecular identification and analysis of a novel human corticotropinreleasing factor $(\mathrm{CRF})$ receptor: the $\mathrm{CRF} 2$ gamma receptor. Molecular Endocrinology 12 1077-1085.

Kravchenco IV \& Furalev VA 1994 Secretion of immunoreactive corticotropin-releasing factor and adrenocorticotropic hormone by T-lymphocytes and B-lymphocytes in response to cellular stress factors. Biochemical and Biophysical Research Communications 204 828-834.

Linton E, Tilders F, Hodgkinson S, Berkenbosch F, Vermes I \& Lowry P 1985 Stress-induced secretion of adrenocorticotropin in rats is inhibited by administration of antisera to ovine corticotropin-releasing factor and vasopressin. Endocrinology 116 966-970.

Lovenberg TW, Chalmers DT, Liu C \& De Souza EB $1995 a$ CRF $2 \alpha$ and CRF $2 \beta$ receptor mRNAs are differentially distributed between the rat central nervous system and peripheral tissues. Endocrinology 136 4139-4142.

Lovenberg TW, Liaw CW, Grigoriadis DE, Clevenger W, Chalmers DT, De Souza EB \& Oltersdorf T $1995 b$ Cloning and characterization of a functionally distinct corticotropinreleasing factor receptor subtype from rat brain. PNAS 92 836-840.

Muglia LJ, Jenkins NA, Gilbert DJ, Copeland NG \& Majzoub JA 1994 Expression of the mouse corticotropin-releasing hormone gene in vivo and targeted inactivation in embryonic stem cells. Fournal of Clinical Investigation 93 2066-2072.

Okosi A, Brar BK, Chan M, D'Souza L, Smith E, Stephanou A, Latchman DS, Chowdrey HS \& Knight RA 1998 Expression and protective effects of urocortin in cardiac myocytes. Neuropeptides 32 167-171.

Ottaviani E, Franchini A \& Franceschi C 1998 Presence of immunoreactive corticotropin-releasing hormone and cortisol molecules in invertebrate haemocytes and lower and higher vertebrate thymus. Histochemical Fournal 30 61-67.

Parkes DG, Vaughan J, Rivier J, Vale W \& May CN 1997 Cardiac inotropic actions of urocortin in conscious sheep. American Fournal of Physiology 272 H2115-H2122.

Perrin MH, Donaldson CJ, Chen R, Lewis KA \& Vale WW 1993 Cloning and functional expression of a rat brain corticotropin releasing factor (CRF) receptor. Endocrinology 133 3058-3061.

Potter E, Behan D, Fischer W, Linton E, Lowry P \& Vale W 1991 Cloning and characterisation of the cDNAs for human and rat corticotrophin releasing factor-binding proteins. Nature 349 423-426.

Potter E, Behan DP, Linton EA, Lowry PJ, Sawchenko PE \& Vale WW 1992 The central distribution of a corticotropinreleasing factor $(\mathrm{CRF})$-binding protein predicts multiple sites and modes of interaction with CRF. PNAS 89 4192-4196.

Potter E, Sutton S, Donaldson C, Chen R, Perrin M, Lewis K, Sawchenko PE \& Vale W 1994 Distribution of corticotropin- 
releasing factor receptor $\mathrm{mRNA}$ expression in the rat brain and pituitary. PNAS $918777-8781$.

Radulovic M, Dautzenberg FM, Sydow S, Radulovic J \& Spiess J 1999 Corticotropin-releasing factor receptor 1 in mouse spleen: expression after immune stimulation and identification of receptor-bearing cells. Fournal of Immunology 162 3013-3021.

Schäfer M, Carter L \& Stein C 1994 Interleukin $1 \beta$ and corticotropin-releasing factor inhibit pain by releasing opioids from immune cells in inflamed tissue. PNAS 91 4219-4223.

Singh VK \& Fudenberg HH 1988 Binding of $\left[{ }^{125} \mathrm{I}\right]$ corticotropin releasing factor to blood immunocytes and its reduction in Alzheimer's disease. Immunological Letters 18 5-8.

Singh VK, Boucher W, Pang XZ, Letourneau R, Seretakis D, Green M \& Theoharides TC 1999 Potent mast cell degranulation and vascular permeability triggered by urocortin through activation of corticotropin-releasing hormone receptors. Fournal of Pharmacology and Experimental Therapeutics 288 1349-1356.

Smith EM, Morrill AC, Meyer WJ \& Blalock JE 1986 Corticotropin releasing factor induction of leukocyte-derived immunoreactive ACTH and endorphins. Nature 321 881-882.
Stephanou A, Jessop DS, Knight RA \& Lightman SL 1990 Corticotrophin-releasing factor-like immunoreactivity and mRNA in human leukocytes. Brain, Behaviour and Immunity 4 67-73.

Torpy DJ, Webster EL, Zachman EK, Aguilera G \& Chrousos GP 1999 Urocortin and inflammation: confounding effects of hypotension on measures of inflammation. Neuroimmunomodulation 6 182-186.

Vale W, Spiess J, Rivier C \& Rivier J 1981 Characterization of a 41-residue ovine hypothalamic peptide that stimulates secretion of corticotropin and $\beta$-endorphin. Science 213 1393-1397.

Vaughan J, Donaldson C, Bittencourt J, Perrin MH, Lewis K, Sutton S, Chan R, Turnbull AV, Lovejoy D, Rivier C, Rivier J, Sawchenko PE \& Vale W 1995 Urocortin, a mammalian neuropeptide related to fish urotensin-1 and to corticotropin-releasing factor. Nature 378 287-292.

Webster EL, Tracey DE, Jutila MA, Wolfe SA \& De Souza EB 1990 Corticotropin-releasing factor receptors in mouse spleen: identification of receptor-bearing cells as resident macrophages. Endocrinology 127 440-452.

REVISED MANUSCRIPT RECEIVED 20 January 2000 